\title{
Urethral Obstruction
}

National Cancer Institute

\section{Source}

National Cancer Institute. Urethral Obstruction. NCI Thesaurus. Code C79804.

Blockage of the normal flow of urine in the urethra. 